ORIGINAL PAPER

\title{
EXPRESSION OF GROWTH HORMONE-RELEASING HORMONE RECEPTORS IN APOCRINE ADNEXAL TUMOURS AND APOCRINE GLANDS OF THE SKIN
}

Bence Kövári ${ }^{1}$, Lajos Kocsis ${ }^{2}$, Erika Varga ${ }^{3}$, Gábor Cserni ${ }^{1,2}$

${ }^{1}$ Institute of Pathology, University of Szeged, Szeged, Hungary

${ }^{2}$ Department of Pathology, Bács-Kiskun County Teaching Hospital, Kecskemét, Hungary

${ }^{3}$ Department of Dermatology and Allergology, University of Szeged, Szeged, Hungary

\begin{abstract}
Encouraged by our previous finding of growth hormone-releasing hormone receptor (GHRH-R) expression in metaplastic and neoplastic apocrine breast epithelium, we examined a small series of skin adnexal tumours with various degrees of apocrine (oxyphilic) differentiation, as well as normal axillary and anogenital apocrine sweat glands, for the expression of GHRH-R.

Sections of formalin-fixed paraffin-embedded tissue blocks were immunostained for gross cystic disease fluid protein-15 (GCDFP-15) and androgen receptor (AR), to prove apocrine differentiation and correlate it with areas of GHRH-R expression. All but one of 19 tumours with apocrine epithelium and all five benign apocrine glands stained with both anti-GHRH-R antibodies used, each labelling a different domain of the receptor. Non-apocrine areas of the tumours and four eccrine tumours without oxyphilic features did not stain, but most sebaceous glands and some eccrine glands were labelled.

Our data suggest that anti-GHRH-R antibodies highlight apocrine differentiation at extramammary sites also. Although GHRH-R seems to have a sensitivity comparable to classic apocrine markers such as AR and GCDFP-15, it seems to be inferior in specificity. The GHRH-R labelling of apocrine glands and neoplastic epithelium might also interfere with the emerging anti-GHRH targeted treatment of some malignancies acting on these receptors.
\end{abstract}

Key words: skin adnexal tumours, sweat gland, apocrine gland, growth hormonereleasing hormone receptor, immunohistochemistry.

\section{Introduction}

Cutaneous adnexal tumours demonstrating non-sebaceous glandular differentiation are classified as either eccrine or apocrine. By derivation from the folliculosebaceous-apocrine unit, gland-forming tumours with a follicular or sebaceous component can generally be interpreted as apocrine in the wide sense of the word [1]. Apocrine differentiation also means a typical phenotype, which is characterised by apical snouts (decapitation or apocrine type secretion) and a relatively large cytoplasm demonstrating eosinophilic granularity, although at times only the latter is present. This morphology has also been referred to as oxyphilic metaplasia. Sometimes the nucleus is also rather large, vesicular, with a prominent nucleolus visible in it. Typical apocrine glands with this morphology include the axillary and anogenital sweat glands or the glands of Moll in the ocular region. A similar morphology is seen in mammary apo- 
crine metaplasia or apocrine differentiation of breast neoplasms, which are oestrogen receptor and progesterone receptor negative by immunohistochemistry (IHC), but show positivity for gross cystic disease fluid protein-15 (GCDFP15) and androgen receptors (AR) [2].

Growth hormone-releasing hormone (GHRH) and its receptors (GHRH-R) have been implicated in carcinogenesis both by means of a classical endocrine mechanism mediated by growth hormone-induced release of insulin-like growth factor from the liver, and as autocrine/paracrine mechanism [3, 4]. In a previous IHC-based study, we identified GHRH-Rs to be rather uniformly present in apocrine metaplasia and carcinomas of the breast $[5,6]$. The morphological similarity of mammary apocrine metaplasia, apocrine breast carcinomas, and adnexal tumours demonstrating apocrine differentiation (oxyphilic metaplasia) prompted us to test for the presence of GHRH-R in the latter.

\section{Material and methods}

Skin adnexal tumours with apocrine differentiation (oxyphilic metaplasia) and normal anogenital or axillary apocrine gland containing tissue blocks were identified from the archives of Bács-Kiskun County Teaching Hospital and the Pathology Laboratory of the Department of Dermatology and Allergology of the University of Szeged. Neutral buffered, formalin-fixed, and paraffin-embedded archival material was used for the study. Apocrine differentiation was verified by light microscopy and the presence of characteristic morphology of oxyphilic metaplasia, as described in the introduction, and was additionally proven by immunohistochemistry for GCDFP-15 and AR (Table I). At least $50 \%$ staining was required with these latter antibodies. Three to four-micrometre-thick sections were immunostained for GHRH-R with antibody ab76263 in all cases and with antibody PA5-33582 in cases where further slides were available (Table I). The ab76263 and PA5-33582 antibodies recognise the $C$-terminal (fourth cytoplasmic) and the $N$-terminal (first extracellular) domains of the GHRH-R protein, respectively. A $10 \%$ cut-off was used to define positive staining with the GHRH-R antibodies, as previously described [5, 6]. Normal cadaver pituitary tissue was used as positive control, and the specimens were evaluated only in the case of adequate positivity.

We also evaluated peritumoural normal sebaceous glands, non-apocrine sweat glands, non-apocrine areas of the tumours showing partial apocrine differentiation, and additionally immunostained 4 eccrine sweat gland neoplasms without apocrine differentiation to test the specificity of GHRH-R antibodies as an apocrine marker.

\section{Results}

Altogether 19 skin adnexal tumours with focal to diffuse apocrine differentiation (oxyphilic metaplasia), five normal apocrine glands, and four sweat gland neoplasms without apocrine differentiation, eccrine poroma $(n=2)$, eccrine cylindroma $(n=2)$, and poroid hidradenoma $(n=1)$ were analysed. The apocrine tumours were diagnosed as apocrine hidrocystoma $(\mathrm{n}=4)$, apocrine cystadenoma $(\mathrm{n}=2)$, tubular/papillary apocrine adenoma $(\mathrm{n}=3)$, chondroid syringoma (mixed tumour) $(\mathrm{n}=4)$, syringocystadenoma papilliferum $(\mathrm{n}=3)$, hidradenoma papilliferum $(n=2)$, and cylindroma $(n=1)$. All cases showed strong GHRH-R positivity in the areas with apocrine differentiation using antibody PA5-33582, and all but one case (the cylindroma with focal apocrine differentiation) were also positive with the antibody ab76263.

Likewise, all five normal axillary or anogenital apocrine glands were positive for both GHRH-R antibodies.

Peritumoural sebaceous glands were mostly positive for both GHRH-R antibodies, but except for two cases of normal non-apocrine sweat glands showing partial staining, the remaining eccrine glands,

Table I. List and applied protocols of primary antibodies

\begin{tabular}{|c|c|c|c|c|c|}
\hline ANTIBODY & $\begin{array}{l}\text { Name } \\
\text { (Clone) }\end{array}$ & IMMUNOGEN EPITOPE & COMPANY & Dilution & $\begin{array}{c}\text { INCUBATION } \\
\text { TIME/TEMPERATURE }\end{array}$ \\
\hline GHRH-R & $\begin{array}{c}\text { ab } 76263 \\
\text { (polyclonal) }\end{array}$ & $\begin{array}{l}C \text {-terminal domain } \\
\text { (50 amino acid) }\end{array}$ & $\begin{array}{c}\text { Abcam } \\
(\text { Cambridge, UK) }\end{array}$ & $1: 250$ & $\begin{array}{c}60 \mathrm{~min} / \text { room } \\
\text { temperature }(\mathrm{RT})\end{array}$ \\
\hline GHRH-R & $\begin{array}{l}\text { PA5-33582 } \\
\text { (polyclonal) }\end{array}$ & $\begin{array}{l}N \text {-terminal domain } \\
\quad(18 \text { amino acid })\end{array}$ & $\begin{array}{l}\text { Thermo Scientific, } \\
\text { (Waltham, MA, USA) }\end{array}$ & $1: 600$ & $30 \mathrm{~min} / \mathrm{RT}$ \\
\hline AR & F39.4.1 & $\begin{array}{l}\text { Amino acids } \\
301-320\end{array}$ & $\begin{array}{c}\text { BioGenex, } \\
\text { (Fremont, CA, USA) }\end{array}$ & $1: 50$ & $30 \mathrm{~min} / \mathrm{RT}$ \\
\hline GCDFP-15 & $23 \mathrm{~A} 3$ & Not specified & $\begin{array}{c}\text { Cell Marque, } \\
\text { (Rocklin, CA, USA) }\end{array}$ & $1: 200$ & $30 \mathrm{~min} / \mathrm{RT}$ \\
\hline
\end{tabular}



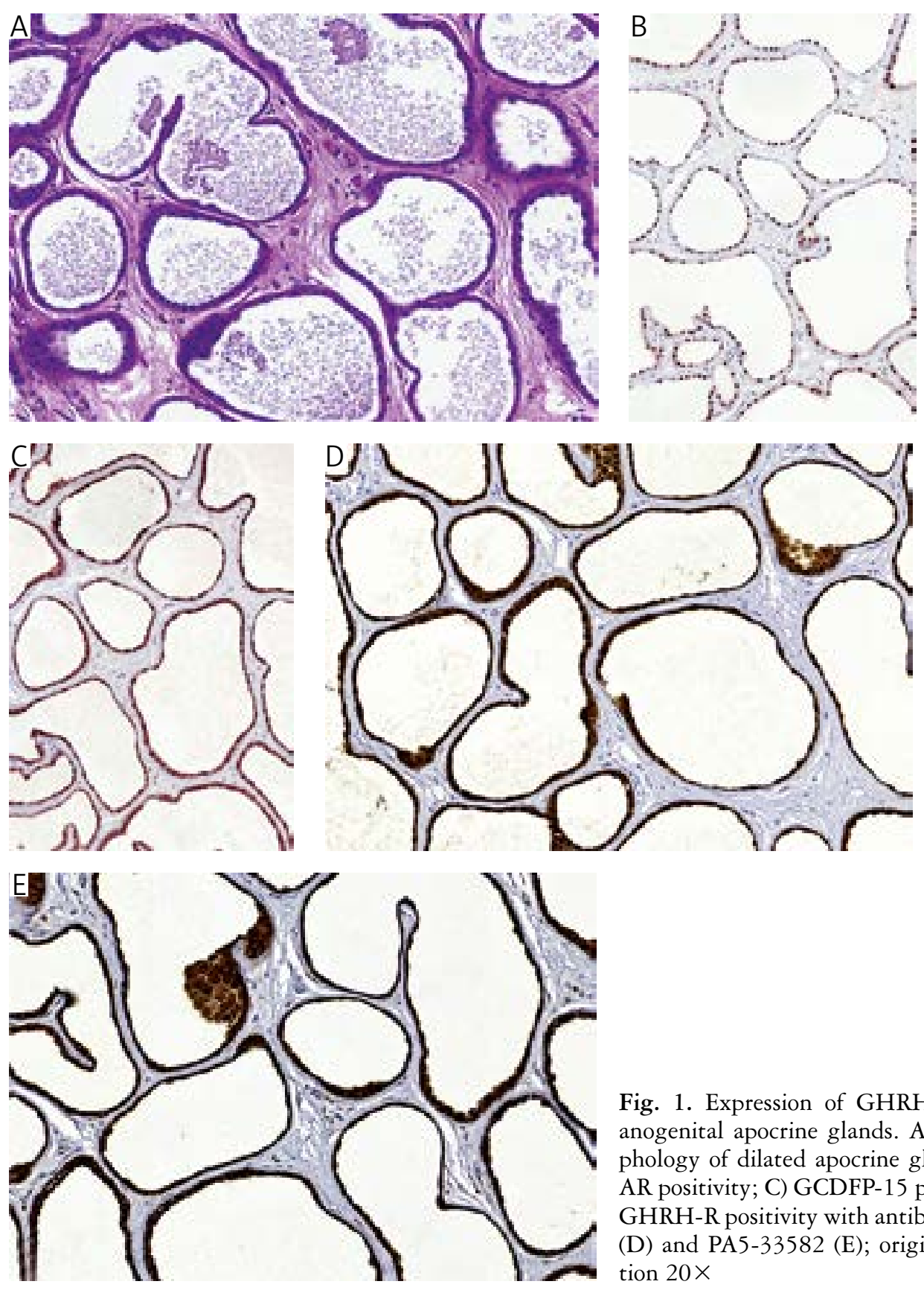

Fig. 1. Expression of GHRH-R in normal anogenital apocrine glands. A) Typical morphology of dilated apocrine glands (HE); B) AR positivity; C) GCDFP-15 positivity; D-E) GHRH-R positivity with antibodies ab76263 (D) and PA5-33582 (E); original magnification $20 \times$

non-apocrine areas of tumours with partial apocrine differentiation and all the four eccrine sweat gland neoplasms without apocrine differentiation tested were negative.

\section{Discussion}

Although apocrine (oxyphilic) differentiation can be recognised on haematoxylin and eosin-stained slides in most cases, sometimes ancillary studies are useful for verification. According to our previous findings, GHRH-R is almost universally expressed in apocrine lesions of the breast [5, 6]. Encouraged by this finding, we analysed the GHRH-R expression of normal cutaneous (anogenital and axillary) apocrine glands and a small series of cutaneous sweat gland neoplasms with apocrine differentiation. GHRH-R was expressed in all the normal apocrine glands and in the apocrine component of all examined cutaneous lesions, suggesting that anti-GHRH-R antibodies could be used as an immunohistochemical marker of apocrine differentiation. According to our data derived from the evaluation of a limited number of cases, GHRH-R as an apocrine marker seems to have a sensitivity comparable to AR and GCDFP-15. As concerns specificity, GHRH-R antibodies are somewhat inferior because other surrounding cutaneous tissues, e.g. sebaceous glands and a few eccrine sweat 

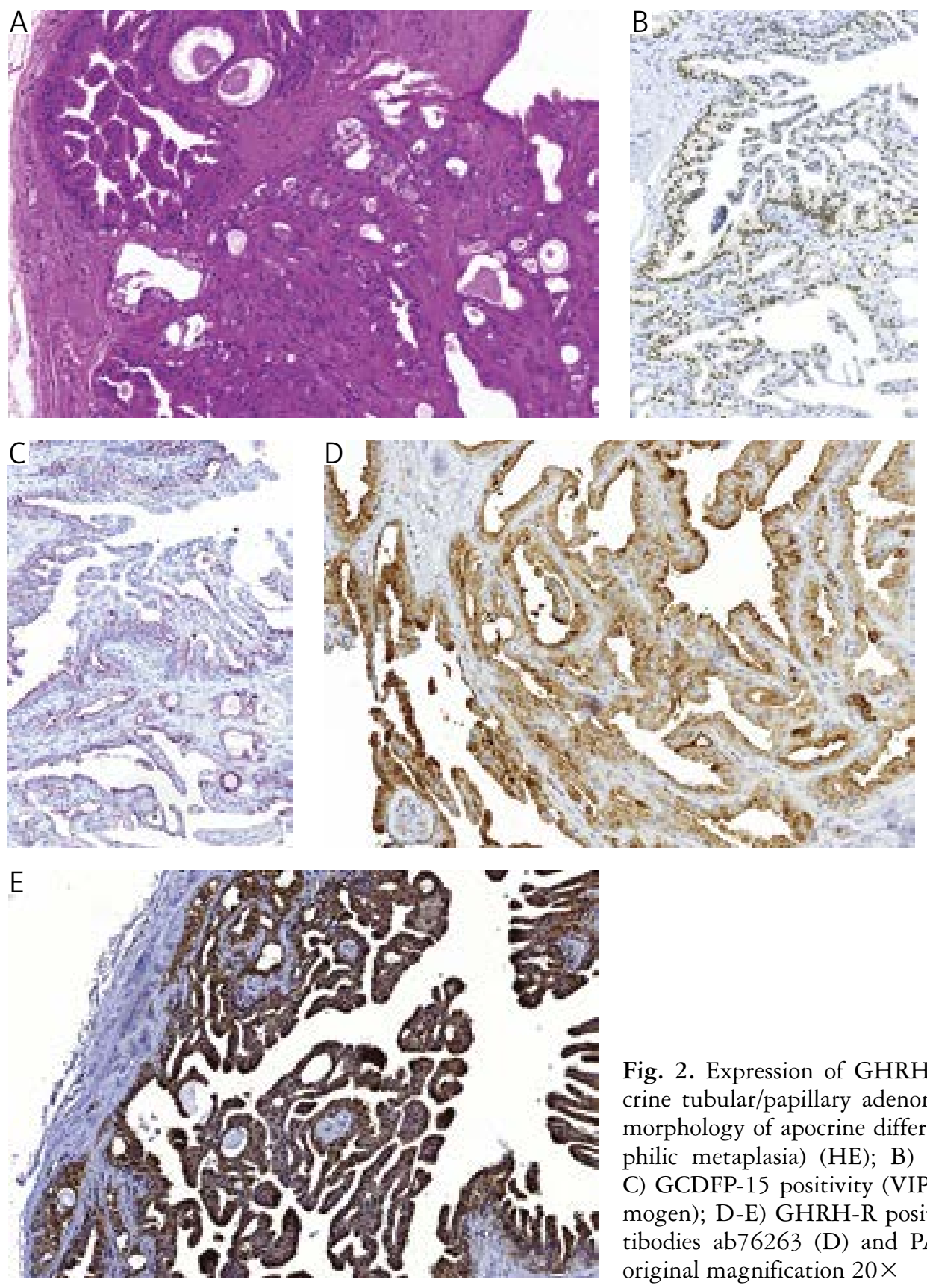

Fig. 2. Expression of GHRH-R in an apocrine tubular/papillary adenoma. A) Typical morphology of apocrine differentiation (oxyphilic metaplasia) (HE); B) AR positivity; C) GCDFP-15 positivity (VIP used as chromogen); D-E) GHRH-R positivity with antibodies ab76263 (D) and PA5-33582 (E); original magnification $20 \times$

glands, were also positive for this marker. To reduce the possibility of non-specific or false staining, we selected two primary GHRH-R antibodies, which were designed to recognise different domains of the GHRH-R protein. Our results on breast carcinomas $[5,6]$ and from this limited series of rare apocrine skin adnexal lesions and representative examples of normal apocrine structures suggest that GHRH-R expression is a relatively uniform, although not fully specific, feature of normal and neoplastic apocrine epithelium.

It is worth noting that GHRH antagonists acting on the GHRH-Rs have been reported to induce significant tumour volume reduction in in vitro studies on triple-negative breast cancer cell lines $[7,8]$. (Most apocrine breast carcinomas also belong to the triple-negative category.) Should anti-GHRH therapy become part of clinically used treatments, it could be anticipated to target apocrine epithelium at any part of the body, and this might manifest as side effects of the treatment. The presence of GHRH-Rs in benign apocrine cutaneous adnexal tumours indicates that GHRH-R expression should be also evaluated in malignant cutaneous tumours with apocrine differentiation, to allow the remote possibility of a targeted anti-GHRH treatment to be explored. 

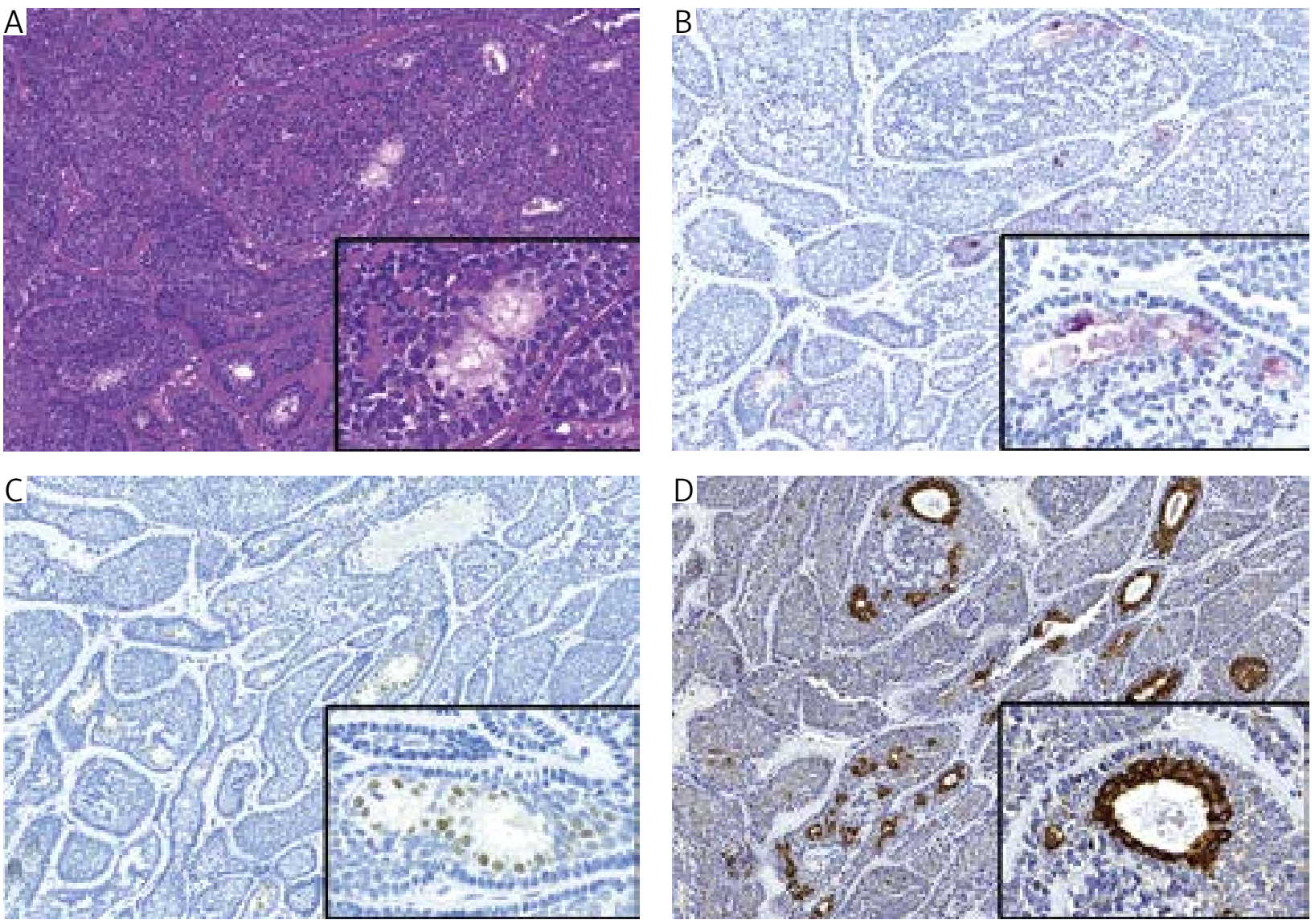

Fig. 3. Expression of GHRH-R in a cylindroma with focal apocrine differentiation. A) Morphology of the focal apocrine differentiation (HE); B) GCDFP-15 positivity (VIP used as chromogen); C) AR positivity; D) GHRH-R positivity with antibody PA5-33582 (the case was negative with antibody ab76263); original magnification $20 \times$; inserts $100 \times$

This work was supported by National Research, Development, and Innovation Office grant number: GINOP-2.3.2-15-2016-00020.

The authors declare no conflict of interest.

\section{References}

1. Kazakov DV, Michal M, Kacerovska D, McKee PH. Lesions with predominant apocrine and eccrine differentiation. In: Kazakov DV, Michal M, Kacerovska D, McKee PH. Cutaneous adnexal tumors. Wolters Kluwer Health/Lippincott Williams \& Wilkins, Philadelphia 2012; 1-171.

2. Vranic S, Schmitt F, Sapino A, et al. Apocrine carcinoma of the breast: a comprehensive review. Histol Histopathol 2013; 28: 1393-1409.

3. Kahán Z, Arencibia JM, Csernus VJ, et al. Expression of growth hormone-releasing hormone (GHRH) messenger ribonucleic acid and the presence of biologically active GHRH in human breast, endometrial, and ovarian cancers. J Clin Endocrinol Metab 1999; 84: 582-589.

4. Barabutis N, Schally AV. Knocking down gene expression for growth hormone-releasing hormone inhibits proliferation of human cancer cell lines. Br J Cancer 2008; 98: 1790-1796.

5. Kövári B, Rusz O, Schally AV, et al. Differential immunostaining of various types of breast carcinomas for growth hormone-releasing hormone $(\mathrm{GHRH})$ receptor - Apocrine epithelium and carcinomas emerging as uniformly positive. APMIS 2014; 122: 824-831.

6. Kövári B, Vranic S, Marchio C, et al. The expression of GHRH and its receptors in breast carcinomas with apocrine differentiation-further evidence of the presence of a GHRH pathway in these tumors. Hum Pathol 2017; 64: 164-170.

7. Seitz S, Rick FG, Schally AV, et al. Combination of GHRH antagonists and docetaxel shows experimental effectiveness for the treatment of triple-negative breast cancers. Oncol Rep 2013; 30: 413-418.

8. Perez R, Schally AV, Popovics P, et al. Antagonistic analogs of growth hormone-releasing hormone increase the efficacy of treatment of triple negative breast cancer in nude mice with doxorubicin; A preclinical study. Oncoscience 2014; 24: 665-673.

\section{Address for correspondence}

\section{Bence Kővári}

Institute of Pathology

University of Szeged

Állomás u. 1

6720 Szeged, Hungary

e-mail: kovari.bence.p@gmail.com 